\title{
Ortho-positronium lifetime studies of free volume in polycarbonates of different structures: influence of hole size distributions
}

\section{Citation for published version (APA):}

Kluin, J. E., Yu, Z., Vleeshouwers, S. M., McGervey, J. D., Jamieson, A. M., Simha, R., \& Sommer, K. (1993). Ortho-positronium lifetime studies of free volume in polycarbonates of different structures: influence of hole size distributions. Macromolecules, 26(8), 1853-1861. https://doi.org/10.1021/ma00060a010

DOI:

10.1021/ma00060a010

Document status and date:

Published: 01/01/1993

\section{Document Version:}

Publisher's PDF, also known as Version of Record (includes final page, issue and volume numbers)

\section{Please check the document version of this publication:}

- A submitted manuscript is the version of the article upon submission and before peer-review. There can be important differences between the submitted version and the official published version of record. People interested in the research are advised to contact the author for the final version of the publication, or visit the $\mathrm{DOI}$ to the publisher's website.

- The final author version and the galley proof are versions of the publication after peer review.

- The final published version features the final layout of the paper including the volume, issue and page numbers.

Link to publication

\footnotetext{
General rights

- You may freely distribute the URL identifying the publication in the public portal. follow below link for the End User Agreement:

www.tue.nl/taverne

\section{Take down policy}

If you believe that this document breaches copyright please contact us at:

openaccess@tue.nl

providing details and we will investigate your claim.
}

Copyright and moral rights for the publications made accessible in the public portal are retained by the authors and/or other copyright owners and it is a condition of accessing publications that users recognise and abide by the legal requirements associated with these rights.

- Users may download and print one copy of any publication from the public portal for the purpose of private study or research.

- You may not further distribute the material or use it for any profit-making activity or commercial gain

If the publication is distributed under the terms of Article 25fa of the Dutch Copyright Act, indicated by the "Taverne" license above, please 


\title{
Ortho-Positronium Lifetime Studies of Free Volume in Polycarbonates of Different Structures: Influence of Hole Size Distributions
}

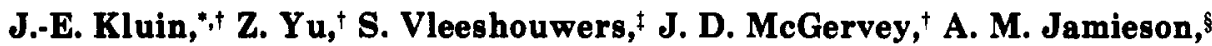 \\ R. Simha, ${ }^{\S}$ and K. Sommer \\ Departments of Physics and Macromolecular Science, Case Western Reserve University, \\ Cleveland, Ohio 44106, Center for Polymers and Composites, Eindhoven University of \\ Technology, 5600 MB Eindhoven. The Netherlands, and Bayer AG, \\ D-5090 Leverkusen, Germany
}

Received September 14, 1992; Revised Manuscript Received December 16, 1992

\begin{abstract}
We have observed certain anomalies in computer fitting of data from positron annihilations in polymers. These suggest to us that some reported ortho-positronium (o-Ps) lifetimes and intensities in these polymers could be artifacts of the computer-fitting procedure. To evaluate this hypothesis, we have developed a computer simulation of experimental data, which can then be used to test the accuracy of the fitting program. The input to this simulation consists of the lifetimes and intensities of any number of positron populations (including para-positronium and free positron decays), plus the spectrometer resolution function, a contribution from annihilation in the positron source, and random background. The simulation uses the computer's random number generator to make the output spectrum resemble an actual experimental curve. The output spectrum is then used as input to the usual fitting program POSFIT, which determines the best-fitting values of lifetime and intensity for three positron lifetime components. When the shortest lifetime, $\tau_{1}$, was fixed at the theoretical value of $120 \mathrm{ps}$, the values of the other lifetimes, $\tau_{2}$ and $\tau_{3}$, were found to be very close to the values in the simulated input. When the simulated input contained several o-Ps lifetime components $-\tau_{3,1}, \tau_{3,2}, \tau_{3,3}$, etc. - the fitted (apparent) value of $\tau_{3}\left(\tau_{3, \text { app }}\right)$ was extremely close to the number-average input value $\left\langle\tau_{3}\right\rangle$. However, the fitted value for the total intensity of these components departed significantly from the total input intensity. The deviations increase drastically when the full width at half-maximum (fwhm) $\geq 280$ ps. Incorporating these new perceptions, we report investigations of the temperature dependence and aging behavior of free volume in glass and melt states for six polycarbonates of different $T_{\mathrm{g}}$ 's. We have also evaluated chemical effects attributable to $\mathrm{e}^{+}$- and $\gamma$-irradiation. In seeking a way to minimize effects of exposure to radiation, we have developed a new method for comparison of rejuvenated samples with well-aged material.
\end{abstract}

\section{Introduction}

It is well understood that the size and concentration of free-volume holes in amorphous polymers influence the chain dynamics and hence play an important role in determining mechanical properties and diffusion phenomena. Thermal expansion implies an increase in the level of free volume and therefore corresponds to a change in the distribution of cavity sizes. In order to predict the properties of amorphous polymers, several theoretical models, based on the free volume concept, have been developed. Measurements of the temperature dependence of the hole free volume, especially of the change in hole size distributions, are therefore very important as a test of current free volume theories and related computer simulations ${ }^{1-3}$ of the polymer melt and glass.

Physical aging of an amorphous polymer, which occurs in the nonequilibrium glassy state, has its origin in the gradual approach to equilibrium and affects all material properties whose temperature and pressure coefficients change drastically at $T_{\mathrm{g}}{ }^{4}$ The physical aging process involves a time-dependent decrease in volume and, like thermal expansion, a corresponding change of the distribution of free volume holes.

The positively charged positron $\left(\mathrm{e}^{+}\right)$is the antiparticle to the electron. Because of the repulsive interaction between $\mathrm{e}^{+}$and the atomic nuclei, $\mathrm{e}^{+}$preferentially samples

\footnotetext{
'Department of Physics, Case Western Reserve University.

‡ Eindhoven University of Technology.

Department of Macromolecular Science, Case Western Reserve University.

il Bayer AG.
}

regions of minimal positive charge density. In the last 2 decades, positron lifetime spectroscopy has become one of the most powerful tools for the investigation of vacancies in metals and semiconductors (see ref 5 for a review). The applicability of positrons to free volume studies in polymers is more complicated because, in addition to annihilating as a free positron with a mean lifetime of less than $500 \mathrm{ps,}$ the positron can capture an electron and form a bound state, a so-called positronium atom $(\mathrm{Ps}){ }^{6,7}$

Ps has an atomic radius similar to hydrogen. Two states of different lifetimes are possible. Para-positronium ( $p$ Ps), consisting of an electron-positron state with antiparallel spins (spin $=0$ ), annihilates after a mean lifetime $\tau_{1}$ of $120 \mathrm{ps}$ to produce two $0.511 \mathrm{MeV} \gamma$-rays. Orthopositronium (o-Ps), an electron-positron state with parallel spins (spin $=1$ ), must generate three $\gamma$-rays in order to conserve spin angular momentum and parity. The ratio of $\mathrm{p}-\mathrm{Ps}$ to $0-P s$ formation equals $1 / 3$. Because the three- $\gamma$ process is much less likely than the two- $\gamma$ decay, the mean lifetime $\tau_{3}$ of o-Ps in vacuum is $142 \mathrm{~ns}$. In condensed matter, however, o-Ps can pick off an electron with antiparallel spin, resulting in a mean lifetime of a few nanoseconds, depending on the electron density of the material surrounding the o-Ps.

Because of its polarizability, Ps samples regions of minimal charge density. Therefore the $o-P s$ wave function is concentrated in free volume holes. Since the annihilation rate of o-Ps is proportional to the overlap of the positron and the pickoff electron wave functions, the o-Ps lifetime is a function of the hole size in which this particle resides. A theoretical model, ${ }^{8,9}$ in which the positronium resides in a spherical potential well of radius $R_{0}$ having an infinite 
potential barrier with an electron layer in the region $R<$ $r<R_{0}$, gives a connection between $\tau_{3}$ and the (spherical) iree volume hole size. Using this semiempirical approach, one can determine the absolute size of free volume holes from this relation:

$$
1 / \tau_{3}=\lambda_{3}=2\left[1-R / R_{0}+1 / 2 \pi \sin \left(2 \pi R / R_{0}\right)\right]
$$

with $R_{0}=R+\Delta R$ and the reasonable assumption that the lifetime of $0-P s$ in the electron layer is the spin-average Ps lifetime of $0.5 \mathrm{~ns}$. A value $\Delta R=0.1656 \mathrm{~nm}$ was determined by fitting experimental $\tau_{3}$-values to data from molecular solids with well-known hole sizes. ${ }^{10}$ This relation holds rigorously only for molecular materials which contain free volume holes of one particular size. However, we have assumed that this value can be used for our polymers, and our data are consistent with this assumption.

A further complication has developed as a result of recent positron lifetime studies. These studies, involving free volume Monte Carlo simulations in Bisphenol A polycarbonate, ${ }^{3}$ have suggested the presence of multiple o-Ps mean lifetimes originating from a distribution of hole sizes; if this is correct, then o-Ps annihilation in such polymers must be described by an apparent lifetime $\tau_{3, \text { app }}$, which is a mean value averaged over all o-Ps components, with corresponding intensity $I_{3 \text {,app. We will discuss this point }}$ in detail in the Computer Simulations section.

The absolute free volume fraction $h$ can be written as

$$
h=\int n\left(v_{\mathrm{f}}\right) v_{\mathrm{f}} \mathrm{d} v_{\mathrm{f}}=\left\langle v_{\mathrm{f}}\right\rangle N
$$

where $n\left(v_{\mathrm{f}}\right) \mathrm{d} v_{\mathrm{f}}$ is the number density of holes whose volume is between $v_{\mathrm{f}}$ and $v_{\mathrm{f}}+\mathrm{d} v_{\mathrm{f}}, N=\int n\left(v_{\mathrm{f}}\right) \mathrm{d} v_{\mathrm{f}}$ is the number of holes per unit volume, and $\left\langle v_{\mathrm{f}}\right\rangle$ is the average hole size. Positron experiments of Kobayashi et al. ${ }^{11}$ on PVAc suggested that $\left\langle\tau_{3}\right\rangle$ can be related to $\left\langle v_{f}\right\rangle$ and that there is a proportionality between $I_{3}$ and $N$. Then $h$ can be written as

$$
h=C I_{3}\left\langle v_{\mathrm{f}}\right\rangle
$$

where $C$ is a constant relating $I_{3}$ to the total number of holes. There follows

$$
I_{3} \sim h /\left\langle v_{\mathrm{f}}\right\rangle
$$

In the first section of the present paper we test the accuracy of eq 3 for Bisphenol A polycarbonate by computer generation of positron lifetime spectra containing $\tau_{3}$ distributions which are the result of the above-mentioned Monte Carlo free volume simulations. We will specify consequences to results of the conventional spectral fitting procedure. In a second section, we discuss effects of the unavoidable positron irradiation of the samples. In a third section, we present results from positron lifetime experiments in several polycarbonates of different $T_{\mathrm{g}}$ 's. Measurements were carried out on rejuvenated samples between 20 and $200^{\circ} \mathrm{C}$. The last section will focus on positron annihilation during physical aging. In order to minimize irradiation damage effects, the polymer samples were separated from the positron source during the thermal treatment procedures. Differences in the extracted $\tau$ - and $I$-values between rejuvenated and aged materials will be discussed.

\section{Methods and Procedures}

(a) Computer Simulations. If the o-Ps lifetime in a polymer does indeed consist of multiple-exponential components with various mean lifetimes, finding the mean lifetime and intensity of each component becomes a serious problem. With an experimental curve involving possibly dozens of variable parameters, the best fit to a presumed theoretical curve is highly suspect. The best that one can hope for is a situation in which the o-Ps components are all considerably longer-lived than the p-Ps or free-positron components. In such a case, it can be possible to find the best fit to a curve that consists of only four distinguishable components, which are (1) p-Ps, (2) free positrons, (3) o-Ps, and (4) positrons annihilated in the source material.

An important aspect of positron experiments in polymers is the influence of hole size distributions and hence of multiple o-Ps lifetimes on the results of data fitting procedures. ${ }^{3,12,13}$ In order to investigate possible consequences, we developed a computer program to simulate positron decay in molecular materials. Events, which are generated randomly, are accumulated to spectra of $1.4 \times 10^{6}$ counts. In addition to any number $i$ of o-Ps components ( $\tau_{3 i}$ and corresponding $\left.I_{3 i}\right)$, the p-Ps $\left(\tau_{1}=\right.$ $120 \mathrm{ps}$ with $I_{1}=I_{3} / 3$ and free positron decays $\left(\tau_{2}=450 \mathrm{ps}\right.$ with $I_{2}=1-I_{1}-I_{3}$ ) are input parameters for each simulation. To ensure conformity with out experiments, a two-component source term $(0.565 \mathrm{~ns}$ with $1.5 \% ; 0.188 \mathrm{~ns}$ with $7.5 \%)$ as well as an average statistical background of 60 counts per channel is included. The finite time resolution of about 260-ps fwhm (Full Width at Half Maximum) of the experiment was synthesized by a final convolution of the spectra with a corresponding Gaussian function.

In order to generate distributions of o-Ps lifetimes for the simulation procedure, we use results of our recent Monte Carlo simulations for Bisphenol A polycarbonate $\left(T_{\mathrm{g}}=416.5 \mathrm{~K}=143.4\right.$ ${ }^{\circ} \mathrm{C}$ ) (see ref 3 for details). The equation-of-state behavior of the amorphous polymer was represented by a partly-filled, disordered lattice model with the temperature-dependent free volume fraction $h(T)$ as a central quantity. Using experimental $P V T$ data on Bisphenol A polycarbonate, ${ }^{14} h(T)$ has been calculated to $\mathrm{be}^{3}$

$h(T)=0.0985+4.88 \times 10^{-4}(T-416.5)$

$$
\text { for } T_{\mathrm{g}}<T<500 \mathrm{~K}(5)
$$

and

$h(T)=0.0985+1.30 \times 10^{-4}(T-416.5)$

$$
\text { for } 300 \mathrm{~K}<T<T_{\mathrm{g}}(6)
$$

in the melt and in the glass, respectively. Therefore, $h\left(T_{\mathrm{g}}\right)$ is approximately 0.1 . With these $h(T)$ values, Monte Carlo simulations (in which free volume in the polymer was computed by filling a fcc-lattice randomly) generated a connection between the degree of occupancy $y=1-h$ and hole size distributions in units of the single-hole volume $v_{1}$. The volume fraction of holes $p_{\text {i }}$ with cluster size $i v_{1}$ could be described as a function of $y$ by the empirical expression

$$
p_{i}=p_{\mathrm{n}} \exp \left(-(i / l(y))^{\alpha(y)}\right) \quad \text { for } 0.8 \leq y \leq 0.99
$$

where $l(y)$ and $\beta(y)$ are polynomial functions of $y$, and $p_{\mathrm{n}}$ is a normalization factor, so that $\sum_{i} p_{i}=1$. Then the number-average hole size $\left\langle v_{f}\right\rangle$ is

$$
\left\langle u_{f}\right\rangle=\sum_{i}\left(p_{i} v_{i} / i\right) / \sum_{i}\left(p_{i} / i\right)=\sum n_{i} v_{i}
$$

and the multiple o-Ps spectrum can be described by

$$
n_{33}(t)=\sum q_{3 i} \exp \left(-t / \tau_{3 i}\right)
$$

where $t$ is the time (respectively channel number) and $n_{3}(t)$ the corresponding number of events. The dependence of $\tau_{3 i}$ on $v_{i}$ is given by eq 1 . In the analysis of positron experiments, the multiple o-Ps decay is fitted by a single-exponential function. As shown in the appendix, if we introduce the apparent o-Ps lifetime $\tau_{i \text {,app }}$ as the fitted value of the long-lived components, we obtain

$$
\tau_{i, \mathrm{Bpp}}=\sum n_{i} \tau_{3 i}
$$

which is simply the number-average lifetime $\left\langle\tau_{3}\right\rangle$ and can be calculated with eqs 1 and 7 from the input parameters of the simulation.

For the multiple o-Ps component simulation we must define the lifetime distribution for each particular value of $h$. Hole sizes are taken into account up to $\sum_{i} p_{1}=0.99$. In order to generate absolute $\tau_{3 i}$ and $I_{3 i}$ values, $v_{1}$ and $I_{3}(h)$ have to be known. 

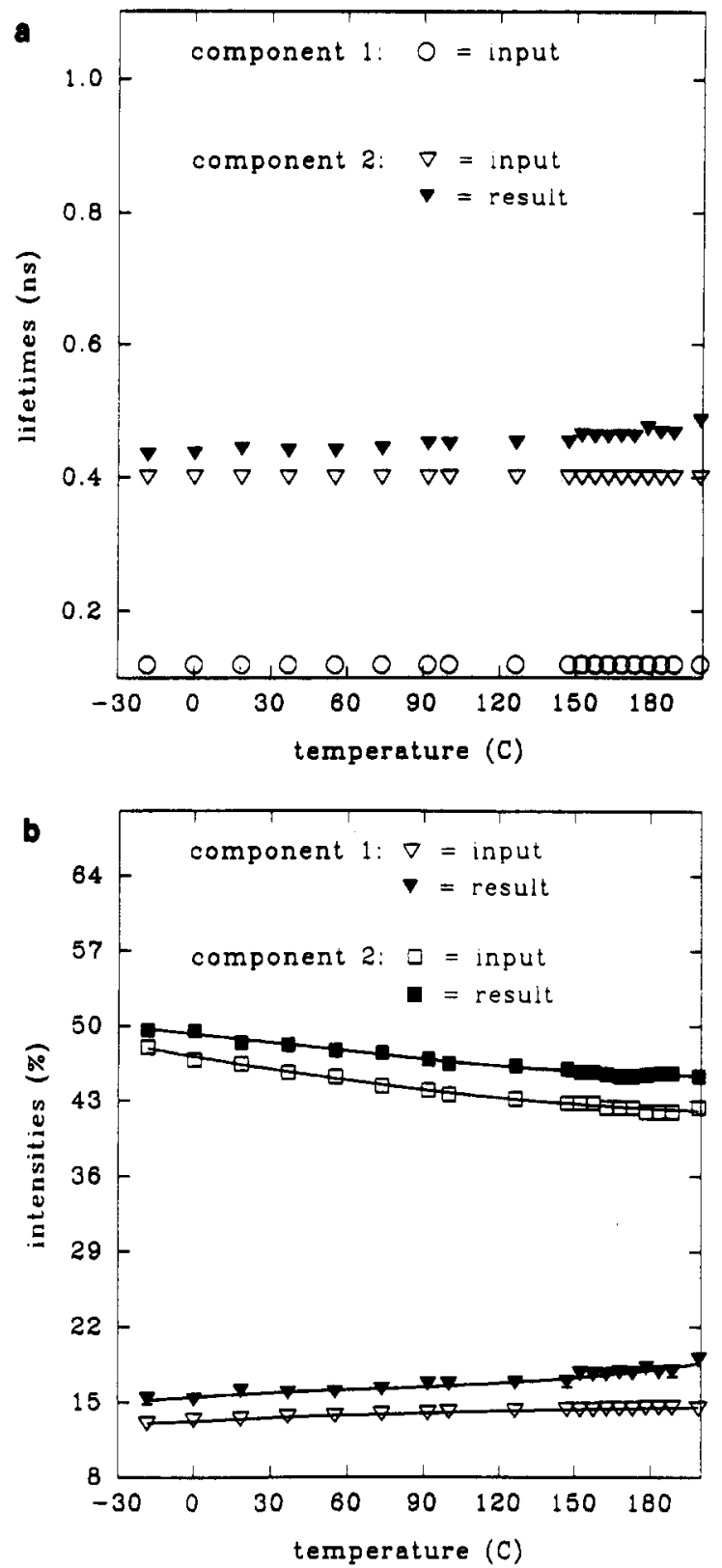

Figure 1. Comparison of $\mathrm{p}-\mathrm{Ps}$ and $\mathrm{e}^{+}$fitting results, evaluated under the constraint $\tau_{1}=120 \mathrm{ps}$, with input values of the simulation: (a) lifetimes $\tau_{1}$ and $\tau_{2}$; (b) intensities $I_{1}$ and $I_{2}$.

Adjusting fitting results to measurements at $T_{k}$, we obtain $v_{1}=$ $65 \AA^{:}$(equal to $\tau_{31}=1.64 \mathrm{~ns}$ ) and $I_{3}(0.1)=43 \%$, respectively. While the model parameter $v_{1}$ is constant, $I_{3}(h)$ is given by eq 4. We use these values as input parameters for all following simulations. Spectra are generated for $7.5 \%<h<12.5 \%$ in steps of $0.25 \%$ corresponding to a temperature range between -40 and $+200^{\circ} \mathrm{C}$.

Subsequently, the programs RESOLUTION and PATFIT $88^{15}$ are employed as described in detail in the next section. First spectra were fitted in a free three-component analysis. We found very large deviations in lifetimes as well as in intensities; these are dependent on $h(T)$, i.e., on the width of the $\tau_{33}$ distribution. As in most positron experiments on polymers, the apparent values $\tau_{\text {l.app }}, \tau_{2 . \text { app }}$, and $I_{1 . a p p}$ were significantly higher than expected.

To provide a more appropriate test, we fitted the same simulated spectra with the p-Ps lifetime constrained to the theoretical value of $120 \mathrm{ps}$. The results are shown in Figures 1 and 2. The values of $I_{1 . \mathrm{ppp}}, \tau_{2 . \mathrm{app}}$ and $I_{2, \mathrm{app}}$ are much closer to the input values than for the free three-component procedure. Also, as shown in Figure $2 a, \tau_{3, \text { app }}$ matches nearly perfectly with $\left\langle\tau_{3}\right\rangle$. Thus, we will constrain $\tau_{1}=120 \mathrm{ps}$ in the subsequent analysis of positron experiments. Unfortunately, however, $I_{3, \text { app }}$ still departs strongly from the input value $I_{i n}$, as seen in Figure $2 \mathrm{~b}$. The presence of a $\tau$; distribution appears to have a substantial effect on the fitted value $I_{3, \text { app. }}$. This can result from the overlap
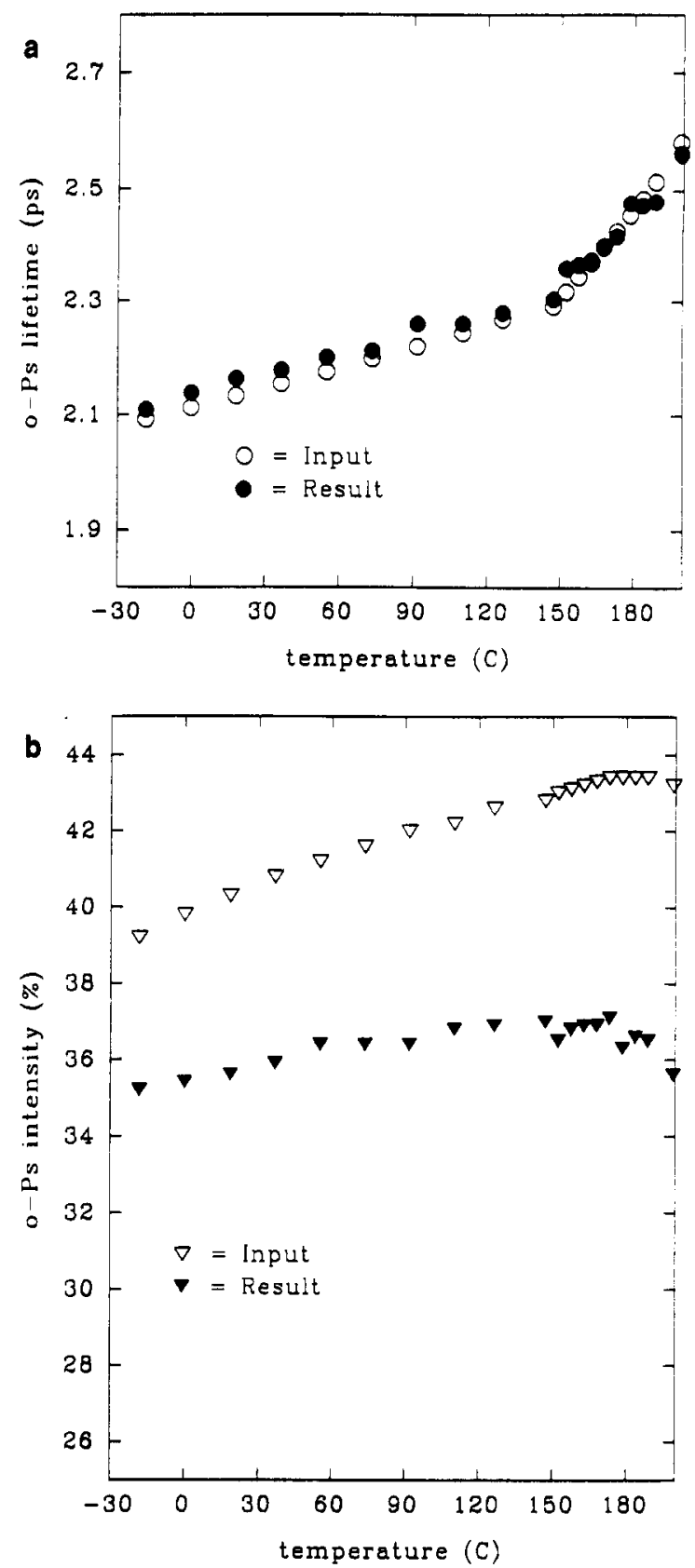

Figure 2. Analysis under constraint $\tau_{1}=120 \mathrm{ps}$. Comparison of fitting results with average input values for the multiple o-Ps decay: (a) lifetimes; (b) intensities.

of the shorter o-Ps lifetimes with the shorter-lived components $\tau_{1}$ and $\tau_{2}$ when the computer fitting is done, causing the fitted value of $I_{2}$ to be higher than its actual value and thus $I_{3, \text { app }}$ to be too small. If this is true, then changes in the time resolution of the spectrometer should affect the fitted values.

In order to check the influence of the time resolution of the spectrometer on the fitted results, we generated a set of spectra which all contain the same hole size distribution $(h=10 \%)$ but are convoluted with different resolution functions of fwhm between 160 and 340 ps. Results of a free three-component procedure are depicted in Figures 3 and 4 . All values are found to be dependent on the resolution. It is highly significant that observed deviations from the input values increase drastically if fwhm exceeds $280 \mathrm{ps}$. In the literature, one finds positron experiments with quite different time resolutions (often larger than $300-p s$ fwhm) applied to polymers. This may explain certain numerical inconsistencies when comparing results on a particular material obtained with different spectrometers. We need to confirm this important result experimentally. Therefore, spectrometers with different time resolutions have been designed. Using each setup, we have measured a well-aged Bisphenol A polycarbonate sample at room temperature (details of the experiment and the analysis are described below). In agreement 

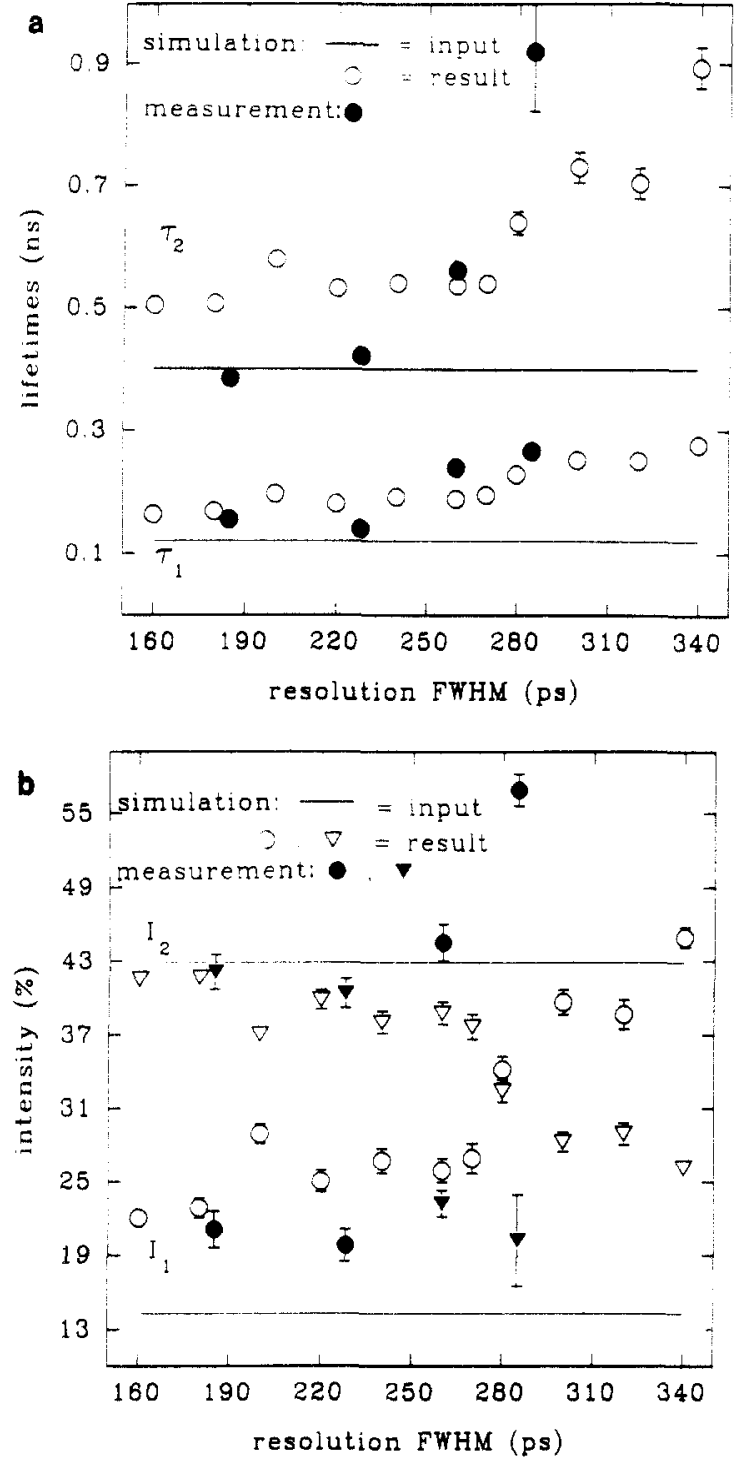

Figure 3. Results of free three-component analysis as a function of fwhm of the time resolution function: (a) lifetimes $\tau_{1}$ and $\tau$; (b) intensities $I_{1}$ and $I_{2}$. Filled symbols depict experimental results.

with our simulations, the results, which are also depicted in Figures 3 and 4 , depend significantly on the precision of the equipment, and all analyzed values show the predicted tendencies.

(b) Experimental Procedure. Disks of 10-mm diameter were machined from polycarbonate sheets of 2-mm thickness, which were kindly provided from Bayer AG, Leverkusen, Germany. The glass transition temperatures $T_{\mathrm{g}}$ (listed in Table I) have been determined using differential scanning calorimetry (DSC) at a heating rate of $20^{\circ} \mathrm{C} / \mathrm{min}$. For lifetime spectroscopy, about $1 \mathrm{MBq}$ of ${ }^{22} \mathrm{NaCl}$ was deposited in an envelope of aluminum foil $(1.7 \mathrm{mg} / \mathrm{cm}$ ) and then sandwiched between two pieces of the sample. The positrons emitted by the ${ }^{22} \mathrm{Na}$ nuclei are annihilated in the sample, producing $0.511-\mathrm{MeV} \gamma$-rays which signal each annihilation. The positron's lifetime is measurable because the daughter nucleus, ${ }^{2-2} \mathrm{Ne}$, emits a $1.275-\mathrm{MeV} \gamma$-rays within $3 \mathrm{ps}$ of the positron's creation. The time interval between these $\gamma$-rays is found by the method described below.

The source-sample sandwich was completely enclosed in a copper sample holder. Heating wires were mounted at two opposite sites of the sample holder, so that a good thermal contact to the sample was guaranteed and temperature gradients could be avoided. Each selected temperature was kept constant within $\pm 0.2^{\circ} \mathrm{C}$ during data acquisition by means of two diode sensors, which were connected to a temperature controller (Model 805) supplied by Lake Shore Cryotronics, Westerville, $\mathrm{OH}$. The entire assembly was placed in a vacuum chamber, which permitted sample heating up to $200^{\circ} \mathrm{C}$. In addition to experiments concerning time-dependent effects of $\mathrm{e}^{+}$-irradiation damage at
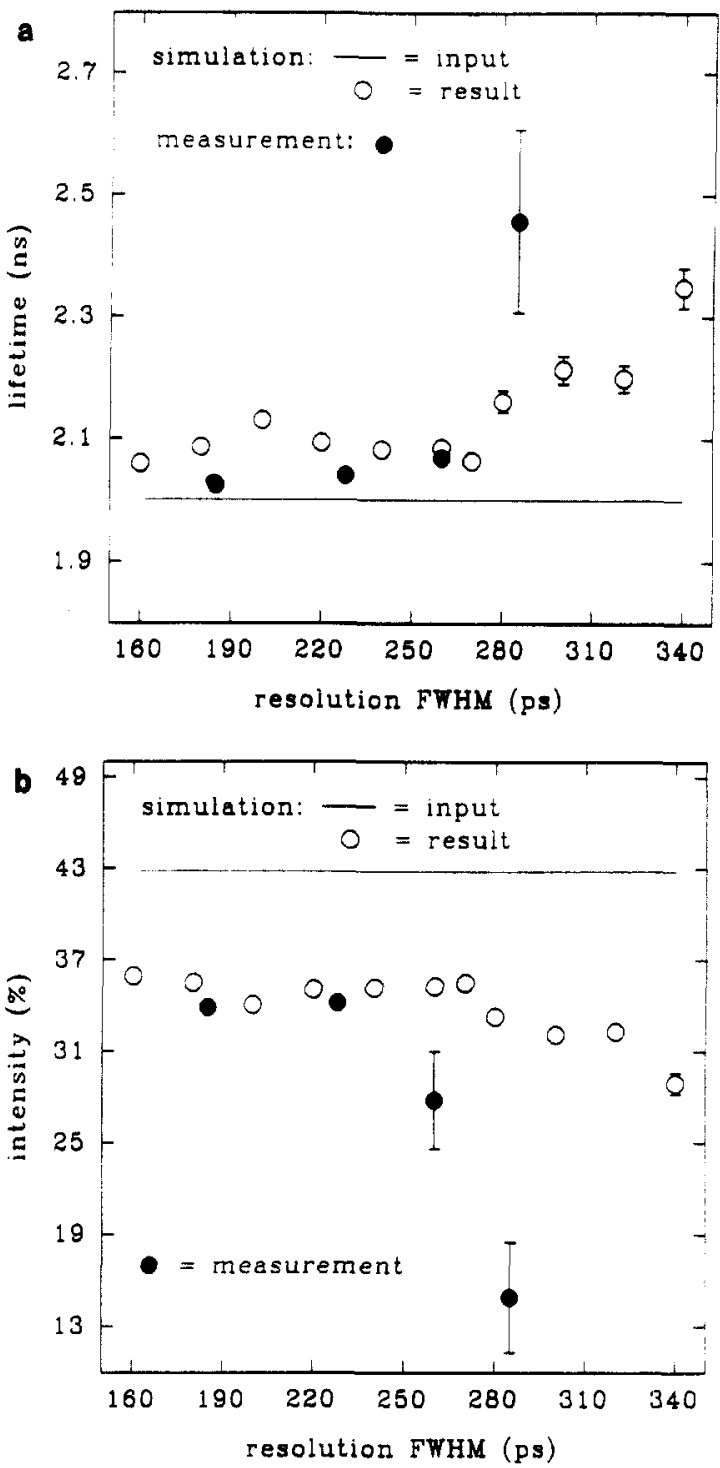

Figure 4. Apparent o-Ps (a) lifetimes, $\tau_{3, \text { app }}$, and (b) intensities, $I_{3, \text { app }}$, as a function of fwhm of the time resolution function. Filled symbols depict experimental results.

$22^{\circ} \mathrm{C}$, measurements as a function of temperature were carried out on six structurally-distinct polycarbonates including two based on Bisphenol A, denoted BPA and TMBPA, and two based on Bisphenol Z, denoted BPZ and TMC, as well as on two statistical copolymers TMBPA (50\%)-BPA (50\%) and TMC $(35 \%)-B P A(65 \%)$

The structures of these polymers are shown in Figure 5. The experiments were performed in a vacuum of about $10^{-3} \mathrm{mbar}$ between room temperature and $200^{\circ} \mathrm{C}$, each temperature point being recorded after annealing at $T_{\mathrm{g}}+5^{\circ} \mathrm{C}$ for $30 \mathrm{~min}$ to remove prior history and then cooling at a rate of $2{ }^{\circ} \mathrm{C} / \mathrm{min}$. Furthermore, the time dependency of free volume relaxation (physical aging) was measured after.a quench from $T_{\mathrm{k}}+5{ }^{\circ} \mathrm{C}$ (cooling rate 2 ${ }^{\circ} \mathrm{C} / \mathrm{min}$ ) to room temperature in BPA and TMBPA.

In order to maximize the free volume relaxation and to minimize $e^{+}$-exposure time, we carried out a second set of measurements on both rejuvenated and aged samples at room temperature. For this purpose, samples were rejuvenated at $T$ $+5^{\circ} \mathrm{C}$ for $30 \mathrm{~min}$ in a vacuum of about $10^{-33} \mathrm{mbar}$, quenched to $23^{\circ} \mathrm{C}$ (cooling rate approximately $150{ }^{\circ} \mathrm{C} / \mathrm{min}$ ), and then connected to the positron source only for the period of the positron measurement. After separation from the $\mathrm{e}^{+}$-source, the same samples were aged at $T_{k}-20^{\circ} \mathrm{C}$ for $12 \mathrm{~h}$. Data were collected again after quench to room temperature. With this method, the total $\mathrm{e}^{+}$-exposure time could be reduced to $2 \mathrm{~h}$ for each set of measurements.

Positron lifetime spectra were collected on a PCA multichannel analyzer (Nucleus Inc., Oak Ridge, TN). A fast-fast lifetime spectrometer was employed, which was based on EG\&G Ortec 
Table I

Characteristic Data of the Investigated Polycarbonates

\begin{tabular}{lccccc}
\hline \multicolumn{1}{c}{ composition } & $T_{\mathrm{g}, \mathrm{p}(\mathrm{s}}\left({ }^{\circ} \mathrm{C}\right)$ & $T_{\mathrm{g}, \mathrm{Dsc}}\left({ }^{\circ} \mathrm{C}\right)^{a}$ & $V_{\mathrm{g}}\left(\AA^{3}\right)$ & $V_{\mathrm{g}} / T_{\mathrm{g}, \mathrm{p}) \mathrm{s}}$ & $\rho\left(\mathrm{g} / \mathrm{cm}^{3}\right)^{\mathrm{a}}$ \\
\hline BPA & $145 \pm 4$ & 150 & $127 \pm 3$ & $0.88 \pm 0.03$ & 1.189 \\
TMBPA-BPA 50/50 & $163 \pm 4$ & 178 & 140.3 & $0.86 \pm 0.03$ & 1.130 \\
TMBPA & $184 \pm 4$ & 192 & $158 \pm 3$ & $0.85 \pm 0.03$ & 1.086 \\
BPZ & $138 \pm 4$ & 174 & $112 \pm 3$ & $0.81 \pm 0.04$ & 1.205 \\
TMC-BPA 35/65 & $160 \pm 4$ & 187 & $149 \pm 3$ & $0.91 \pm 0.04$ &
\end{tabular}

a Data provided by Bayer AG, Leverkusen, Germany. Density $\rho$ is at room temperature.<smiles>CC(C)(C)Oc1ccc(C(C)(C)c2ccc(OC3CC4CCC3C4)cc2)cc1</smiles>

BPA

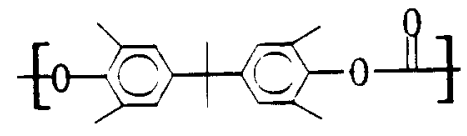

TMBPA<smiles>CC(C)(C)Oc1ccc(C2(c3ccc(OC4CCC4)cc3)CCCCC2)cc1</smiles>

BPZ

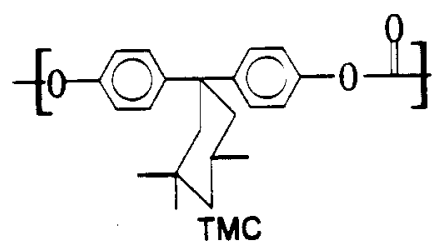

Figure 5. Structures of the polycarbonates investigated in this work.

NIM modules [e.g., Model 583 constant-fraction discriminators (CFD) and a Model 566 time-to-amplitude converter (TAC)] To optimize the resolution as well as the efficiency of the spectrometer, a cylindrical CsF-crystal of 1.5 -in. length and 1.5in. diameter (Solon Technologies, Inc., Ohio) coupled by glycerol ${ }^{16}$ to a photomultiplier tube (Type H2431, Hamamatsu, Japan), was used to detect the $1.275-\mathrm{MeV} \gamma$-rays which indicate the "birth" of a positron. In order to detect the $0.511-\mathrm{MeV}$ annihilation $\gamma$-ray, a conical BaF-crystal of 0.8-in. and 1.0-in. diameters and 1.0-in. length ${ }^{17}$ (Solon Technologies, Inc., Ohio) likewise mounted to a photomultiplier tube (Type $\mathrm{H} 2431 \mathrm{Q}$, Hamamatsu, Japan) was employed. With an appropriate window setting of both CFD's, spectra which contained about 1.2 million counts were collected within $30 \mathrm{~min}$ (count rate $670 \mathrm{cps}$ ) with 260-ps fwhm time resolution.

For the analysis of the spectra the fit program PATFIT $88^{15}$ was employed. A two-component source term $(0.5651 \mathrm{~ns}$ with $1.5 \% ; 0.1883 \mathrm{~ns}$ with $7.5 \%$ ) was subtracted uniformly from each spectrum. In order to determine the resolution function, several spectra were fitted from the left-hand side of the peak into the background on the right-hand side by means of the program RESOLUTION. ${ }^{15}$ The resolution function was approximated as a sum of three Gaussians whose statistical weights and fwhm as well as the time-zero channel were determined by the fitting program. The resolution function was found to be identical and fixed during the final three-component analysis. Spectra were analyzed from the peak well into the backgound on the right side. The $\chi^{2 /} / \nu$ values were always between 0.9 and 1.2 . There were no constraints for lifetimes and corresponding intensities,

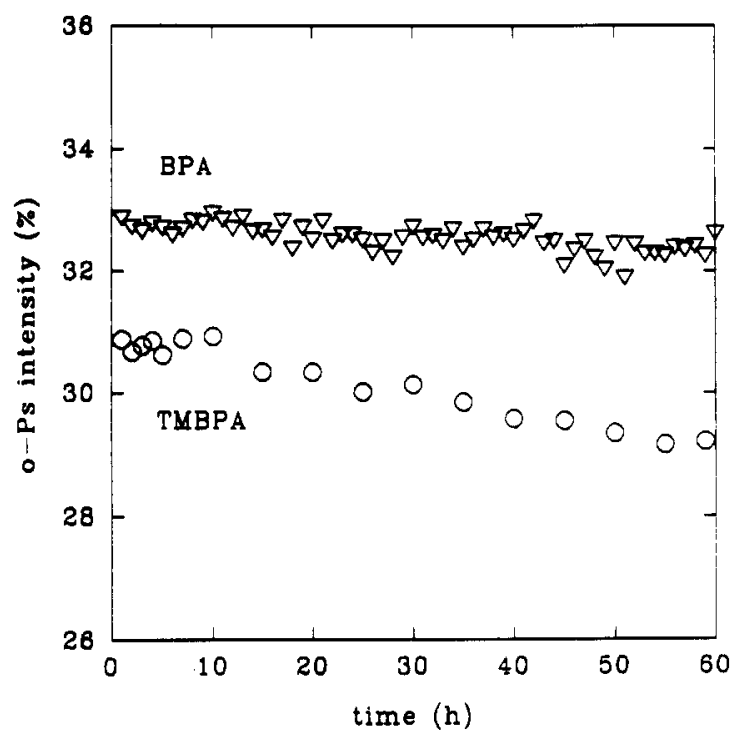

Figure 6. Influence of irradiation time on o-Ps intensity, $I_{3, \text { app }}$, for BPA-PC and TMBPA-PC. Data were collected at $23^{\circ} \mathrm{C}$.

except $\tau_{1}=120 \mathrm{ps}$ and $I_{1}+I_{2}+I_{3}=1$. The background and the time-zero channel were free-fit parameters.

\section{Experimental Results and Discussion}

(a) Effects of $\mathrm{e}^{+}$-Irradiation. Recently it has become clear $^{18}$ that positron irradiation can cause damage in molecular samples which influences the positron annihilation behavior and thus modifies measured spectral parameters. Precise investigations of this effect are very important to establish credibility of free-volume measurements by positron annihilation. Therefore, we first evaluated the dependence on exposure time of the key parameters $\tau_{3 \text {,app }}$ and $I_{3 \text {,app. In agreement with our previous }}$ investigation ${ }^{13}$ and recent measurements of Welander and Maurer, ${ }^{18}$ no effect of irradiation time on $\tau_{3, \text { eff }}$ is observed, independent of the material. However, $I_{3 \text {,app }}$ always decreases with time, although the magnitude of this effect is dependent on the particular material and varies, for example, among the polycarbonates investigated in this study. As an illustration, variation of $I_{3, \mathrm{app}}$ with exposure time in BPA and TMBPA is depicted in Figure 6. Hence, in all following free volume studies, $I_{3, \text { app }}$ is unavoidably influenced to different extents by irradiation damage. Since the simulations above have established that artifacts of the fitting procedure result in distribution-dependent deviations of the apparent $I_{3 \text {,app }}$ from the input value $I_{3}$, the measured $I_{3, \text { app }}$ cannot be quantitatively interpreted as a measure of the number of free volume holes in the polymer. Thus we will defer any discussion of these data for the investigation of the temperature dependence of free volume. Instead, we will focus here on the interpretation of $\tau_{3, a p p}$, which was found to be free from artifacts of the analysis as detailed above.

(b) Temperature Dependence of Free Volume. Figure 7 compares the experimental values of the average o-PS lifetimes, $\tau_{3, \mathrm{app}}$, as a function of temperature in the 


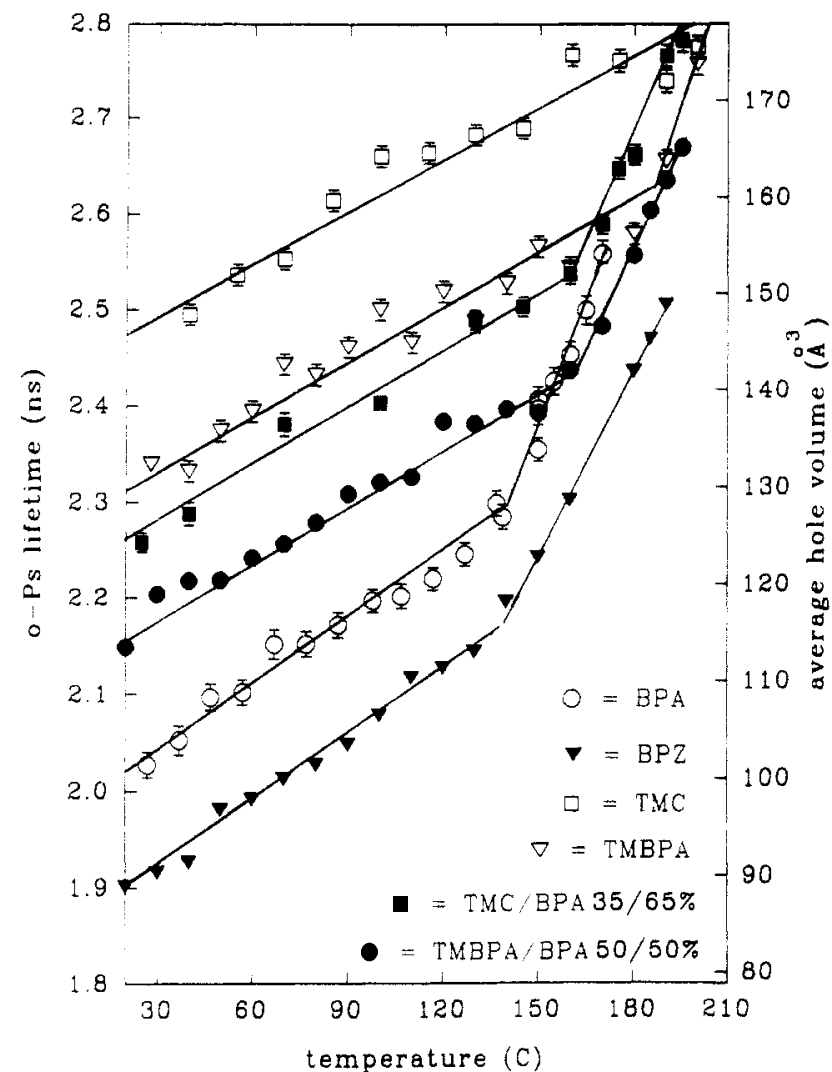

Figure 7. Apparent o-Ps lifetime, $\tau_{3, a p p}$, and the corresponding average hole volume, $\left(V_{\text {hule }}\right)$, as a function of temperature for investigated polycarbonates. Each curve can be approximated by two linear functions, whose intersection defines a glass transition temperature, $T_{\mathrm{g}, \mathrm{pus} \text {. }}$.

investigated polycarbonates. The free volume units on the right-hand side vertical axis are computed from the $\tau_{3, \text { app }}$ via eq 1 . Clearly, the average hole sizes $V_{\text {hole }}$ at a particular temperature vary significantly in these materials. In the glassy state, the slopes of $V_{\text {hole }}(T)$ (i.e., the thermal expansion coefficients of the holes $\alpha_{\text {hole, }}$ ) in all polycarbonates measured in this work can be approximated by a single value $\alpha_{\text {hole, }}=1.7 \times 10^{-3} / \mathrm{K}$. In the melt, $\alpha_{\text {hole, }}$ varies between $7 \times 10^{-3} / \mathrm{K}$ and $10 \times 10^{-3} / \mathrm{K}$. In our recent positron study in BPA, ${ }^{13}$ we found $\alpha_{\text {hole, }}=2.5 \times 10^{-3} / \mathrm{K}$ and $\alpha_{\text {hole, }}=7.2 \times 10^{-3} / \mathrm{K}$ after a free three-component analysis of the positron experiment. The intersection of both linear functions defines a glass transition temperature, $T_{\mathrm{g}, \mathrm{pos}}$, with values listed in Table $\mathrm{I}$. Likewise, corresponding $T_{\mathrm{g}}$ 's determined by means of differential scanning calorimetry at a heating rate of $20^{\circ} \mathrm{C} / \mathrm{min}$ are given. $T_{\mathrm{g}, \text { pos }}$ was found to be always lower than $T_{\mathrm{g}, \mathrm{DSC}}$. While a difference of $5-10^{\circ} \mathrm{C}$ could be plausibly assigned to the slower cooling rate $\left(2^{\circ} \mathrm{C} / \mathrm{min}\right)$ in the positron experiment, the reason for discrepancies of as much as 30 ${ }^{\circ} \mathrm{C}$ in BPZ and TMC/BPA (35/65) is presently unclear. This would not be inconsistent with the idea that, because of its small size, o-Ps is sensitive to smaller holes which remain unfrozen for some temperature range below the $T_{\mathrm{g}}$ observed by DSC.

It is interesting to note that the experimental hole volumes at $T_{\text {g,pos }}$, viz., $V_{\mathrm{g}}\left(T_{\mathrm{g}, \mathrm{pos}}\right)$, exhibit an increasing trend with $T_{\mathrm{g}, \mathrm{pos}}$, as shown in Figure 8 and in Table I, where the ratios $V_{g} / T_{\mathrm{g}, \text { pos }}$ are seen to be rather similar. This is qualitatively consistent with the deductions of the statistical theory and with physical intuition, i.e., that "low$T_{\mathrm{g}}$ systems should require relatively few holes to pass into the liquid state". ${ }^{19}$ A more detailed comparison with theory must await determination of PVT data for these polymers. It is pertinent to note, however, that the average
190

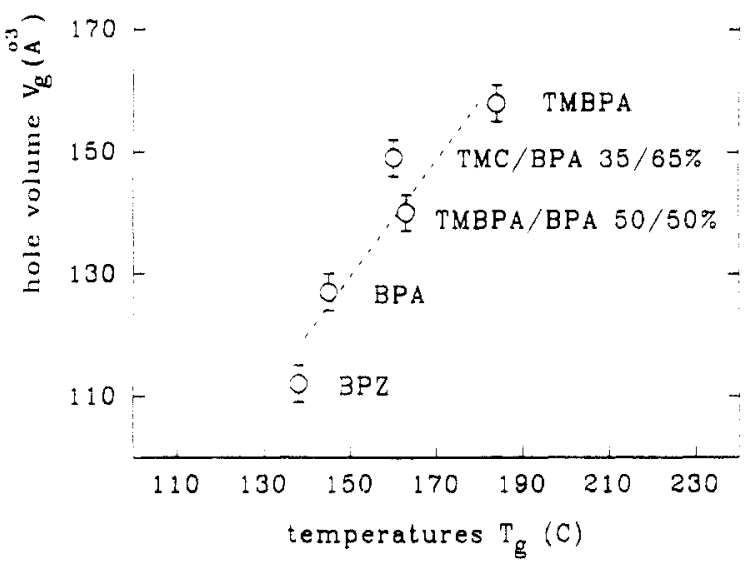

Figure 8. Average free volume hole size $\left\langle V_{\text {hole }}\left(T_{k, p \text { on }}\right)\right\rangle$ at the glass transition vs glass temperature $T_{\text {k.pus. }}$.

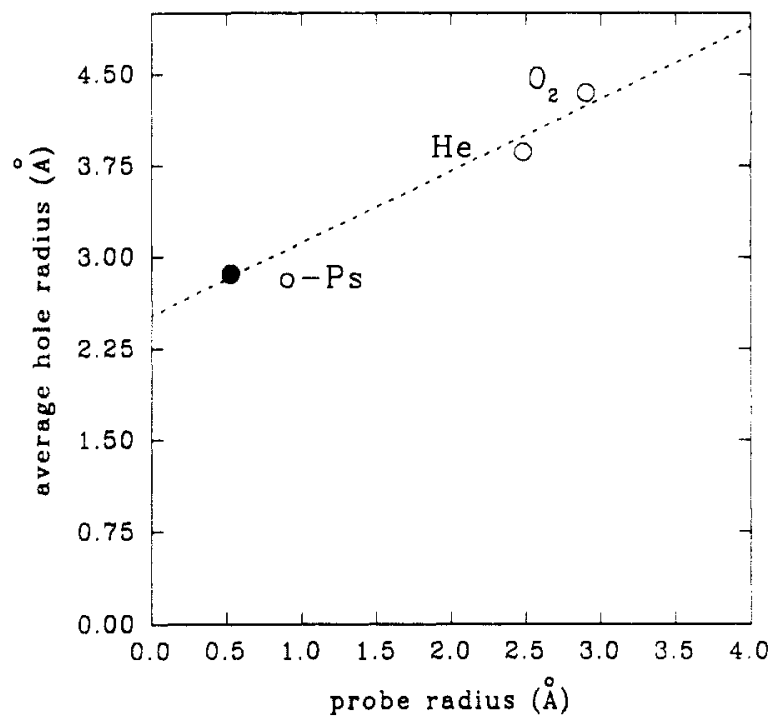

Figure 9. Average hole radii sampled in BPA by different diffusants. Depicted data for $\mathrm{He}$ and $\mathrm{O}_{2}$ (open circles) are based on calculations of Arizzi et al. $;^{19}$ the value for o-Ps (filled circle) is measured in this work.

hole volume of each polycarbonate (Figure 7) shows an inverse correlation with bulk densities at room temperature (cf. $V_{\mathrm{g}}$ and $\rho$ in Table I).

Recently, Arizzi et al. ${ }^{20}$ reported results from a molecular mechanics simulation of glassy microstructure in BPAPC. The shapes and dimensions of clustered portions of the empty space available to different diffusants $\left(\mathrm{He}, \mathrm{O}_{2}\right.$, $\mathrm{N}_{2}$ ) were analyzed. The polymer was represented as a rigid matrix of hard-sphere atoms, and the unoccupied volume was defined by a Delaunay tetrahedral construction. The calculations produced distributions of different cluster sizes available for diffusion of the above-mentioned penetrants, which were determined by their van der Waals radii. The overwhelming majority of clusters was found to be of very low anisotropy and hence of rather spherical shape. Using their results for $\mathrm{He}$ and $\mathrm{O}_{2}$, we can calculate the corresponding o-Ps lifetime distributions by means of eq 1 . The average lifetime $\left\langle\tau_{3}\right\rangle$, i.e., $\tau_{3 . \text { app }}$, is given by eq 10 , and corresponding average hole radii are then calculated with eq 1 ; they represent fictitious values which would be observed by positron annihilations if o-Ps had the same size as $\mathrm{He}$ or $\mathrm{O}_{2}$. The results are depicted in Figure 9, which plots the calculated average hole radii versus the corresponding probe radii (open circles). Using a van der 

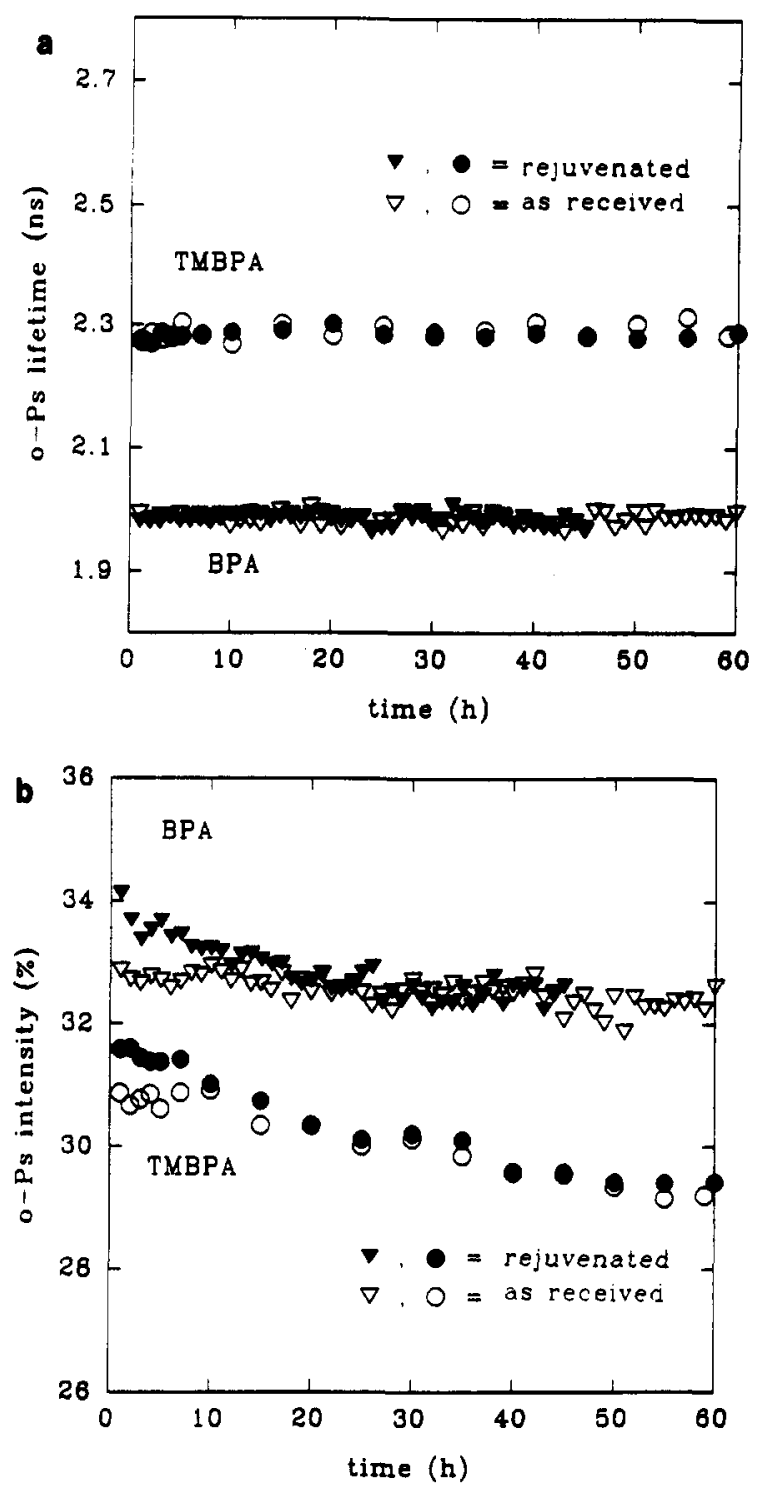

Figure 10. Dependence of (a) o-Ps lifetimes, $\tau_{3, \text { app }}$ and (b) intensities, $I_{3, \text { app }}$, on time after quench from $T_{\mathrm{g}}+5^{\circ} \mathrm{C}$ to $23^{\circ} \mathrm{C}$ in TMBPA and BPA compared to irradiation effects.

Waals radius $r_{0-P_{s}}=0.53 \AA$ to characterize the o-Ps size, we can compare our positron measurements with the investigation above (indicated as a filled circle in Figure 9). It is interesting to note that all three results can be approximated by a linear function; i.e., measured average hole radii increase linearly with the size of the probe. However, a more rigorous test would be to carry out molecular mechanics simulations using an o-Ps probe. In addition, as pointed out by Arizzi et al.., ${ }^{20}$ some caution must be exercised in interpreting these unoccupied volumes as free volumes since the simulations do not incorporate thermal motions.

(c) Physical Aging. The gradual approach of the glassy state to equilibrium is investigated in BPA and TMBPA. Since only a small change in the distribution is expected on physical aging, as compared to temperature effects, we will focus here on lifetimes and intensities of the o-Ps annihilation and, in a second set of measurements, on the p-Ps decay as well. Figure 10 shows the time behavior of the o-Ps lifetime (a) and the corresponding intensity (b) for samples after quench from $T_{\mathrm{g}}+5^{\circ} \mathrm{C}$ to $23^{\circ} \mathrm{C}$ with a cooling rate of $2{ }^{\circ} \mathrm{C} / \mathrm{min}$ in comparison to measurements in as-received material. While no aging effect is visible in the o-Ps lifetime within the scatter of the data, a significant difference is evident in the intensity between the rejuvenated and the as-received samples for approximately the first $10 \mathrm{~h}$ after quench. This effect seems to be larger in BPA than in TMBPA. As in our previous investigation on BPA, the decrease of $I_{3}$ suggests that physical aging reduces the free volume fraction in both samples, while the change of $\tau_{3}$ seems to be only of minor importance. However, note that (especially for TMBPA) $I_{3}$ in the asreceived material decreases with $\mathrm{e}^{+}$-exposure time. Therefore, the magnitude of the change due solely to aging effects may have been overestimated in previous positron studies. We conclude that only a comparison of positron measurements in polymers after quench with those in the "old" material can give evidence about the time dependence of free volume relaxation in polymers after quench.

In order to maximize the contribution from the free volume relaxation and to minimize that due to $e^{+}$-exposure time, we investigated positronium decay in samples rejuvenated at $T_{\mathrm{g}}+5^{\circ} \mathrm{C}$ for $30 \mathrm{~min}$ and in samples aged at $T_{\mathrm{g}}-20^{\circ} \mathrm{C}$ for $12 \mathrm{~h}$, each measured after a rapid quench to $23^{\circ} \mathrm{C}$ (cooling rate approximately $150^{\circ} \mathrm{C} / \mathrm{min}$ ). For better statistics, data were collected four times every 30 min after quench. During thermal treatment, samples were separated from the positron sources. Figure 11 shows the results for BPA. Apparently, the average free volume relaxed about $3 \AA^{3}$, a value only slightly above the statistical error of our measurement. The corresponding $I_{3, \mathrm{app}}$, however, decreases more significantly, by about $3 \%$. In contrast, the apparent intensity of p-Ps, $I_{1, a p p}$, rises nearly $4 \%$. This could be due to an increase of the contribution of short o-Ps, components in $I_{1, \text { app }}$. We therefore interpret this behavior as an indication that the hole size distribution in BPA is indeed shifted during the aging process or, in other words, that bigger holes relax more rapidly than smaller ones. In TMBPA, the measurable free volume relaxation after aging is found to be much smaller than in BPA (Figure 12). This suggests that the aging rate for free volume in TMBPA is slower than in BPA at the identical distance of $20^{\circ} \mathrm{C}$ below the respective $T_{\mathrm{g}}$ 's.

\section{Conclusions}

We present results of computer simulations of positron annihilation in Bisphenol A polycarbonate, performed to investigate the influence of hole size distributions on the conventional spectroscopic fitting procedures. We generated spectra which contained all parameters encountered in the positron experiment, namely, multiple o-Ps decays, $\tau_{3 i}$, and $I_{3 i}$, with an average lifetime $\left\langle\tau_{3}\right\rangle=\sum_{i} p_{i} \tau_{3 i}, \mathrm{p}-\mathrm{Ps}$ annihilation with $\tau_{1}=120 \mathrm{ps}$ and $I_{1}=I_{3} / 3$, as well as a free positron lifetime $\tau_{2}=400 \mathrm{ps}$ with $I_{2}=1-I_{1}-I_{3}$. A source term and a statistical background were also integrated, and spectra were convoluted with a typical resolution function. Finally, spectra were analyzed by means of the PATFIT 88 program, first in a free threecomponent fitting procedure.

As found in most positron experiments on polymers, fitted p-Ps lifetime parameters $\tau_{1, \text { app }}$ and $I_{1, \text { app }}$ showed significantly higher values than expected. Furthermore, the analyzed o-Ps lifetime $\tau_{3, \text { app }}$ with $I_{3, \text { app }}$ deviated significantly from the input $\left\langle\tau_{3}\right\rangle$ and $I_{3}$. Apparently, the distribution of o-Ps components resulted in artifacts of the fitting procedure, the magnitudes of which are found to be strongly dependent on the fwhm of the resolution function. This result, which has been confirmed experimentally, may explain certain numerical inconsistencies when comparing results on a particular material obtained with different spectrometers. In a second analysis, the fitting procedure was constrained by fixing $\tau_{1}$ at $120 \mathrm{ps}$. When this is done, $\tau_{3, \text { app }}$ matches nearly perfectly with the input $\left\langle\tau_{3}\right\rangle . I_{3, \text { app }}$, however, still departs significantly from $I_{3}$, the amount of deviation being dependent on the resolution function. 

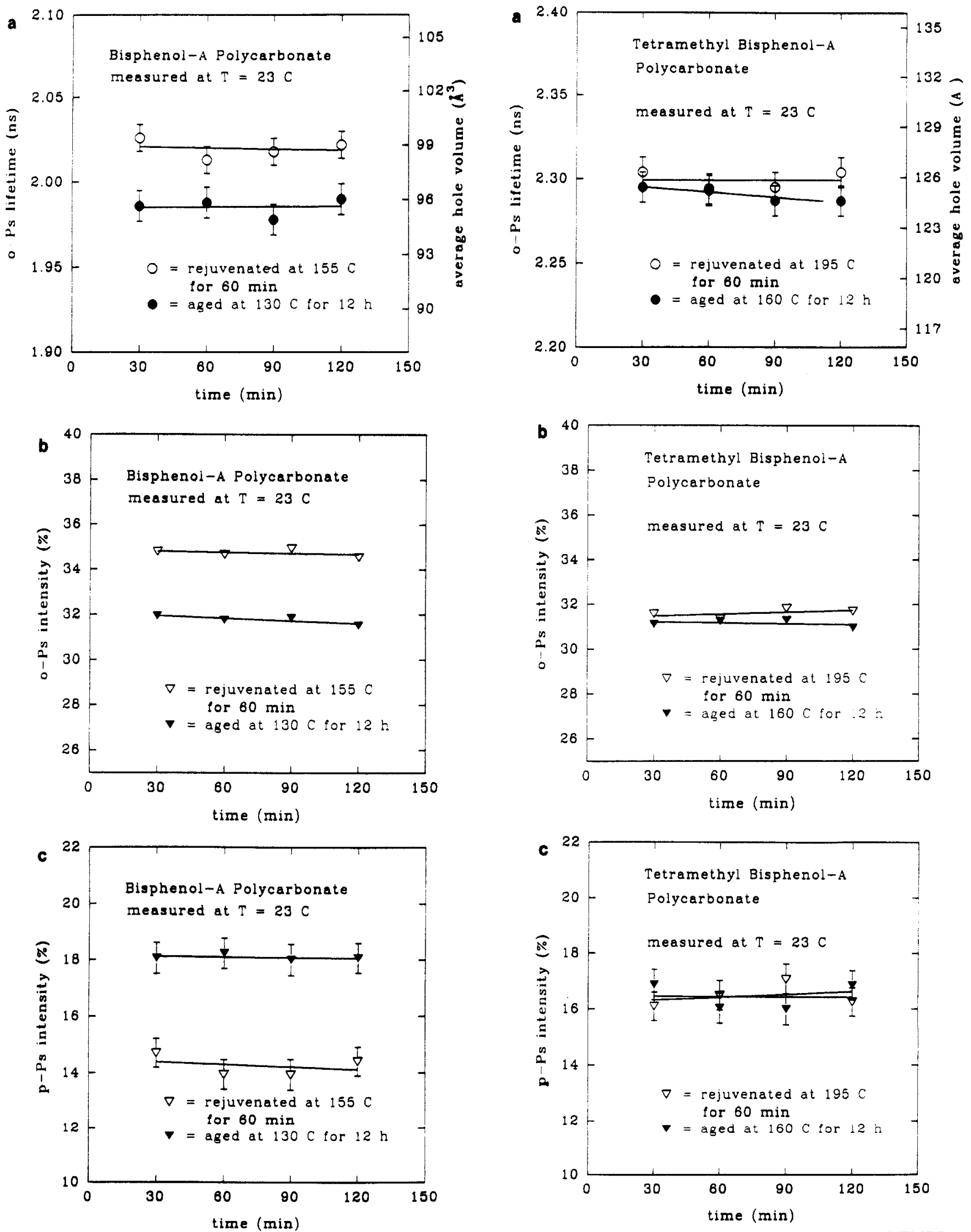

Figure 11. Comparison of o-Ps decay in rejuvenated BPA with material aged for $12 \mathrm{~h}$ at $130^{\circ} \mathrm{C}$ : (a) o-Ps lifetime, $\tau_{3, \text { app }}$, and the corresponding average hole volume, $\left(V_{\text {holl }}\right)$; (b) o-Ps intensity, $I_{3, \text { app }} ;$ (c) p-Ps intensity, $I_{1, \text { app }}$, vs irradiation time.

In the experimental section we present results of an investigation of the temperature dependence of the o-Ps decay in polycarbonates of different $T_{\mathrm{g}}$. Taking account of the perceptions gained in the simulations of the analysis procedure, we can relate $\tau_{3, a p p}$ to $\left\langle\tau_{3}\right\rangle$ and hence to the

Figure 12. Comparison of o-Ps decay in rejuvenated TMBPA with material aged for $12 \mathrm{~h}$ at $130^{\circ} \mathrm{C}$ : (a) o-Ps lifetime, $\tau_{3, \text { app }}$ and the corresponding average hole volume, $\left\langle V_{\text {hole }}\right\rangle ;$ (b) o-Ps intensity, $I_{3, \mathrm{app}}$; (c) p-Ps intensity, $I_{1, \mathrm{app}}$, vs irradiation time.

average size of free volume holes $\left\langle V_{\text {hole }}\right\rangle$. We found an increasing trend of $\left\langle V_{\text {hole }}\right\rangle$ with increasing $T_{\mathrm{g}}$, which is qualitatively consistent with deductions of the statistical theory of Simha and Somcynsky. ${ }^{1}$ A comparison of our results for BPA with a molecular mechanics study of Arizzi 
et al. ${ }^{20}$ indicates that the hole volume $\left\langle V_{\text {hole }}\right\rangle$ measured by $o$-Ps is numerically reasonable in view of the known o-Ps radius. Furthermore, we measured physical aging in BPA and TMBPA with consideration of possible artifacts due to $\mathrm{e}^{+}$-irradiation. Distinct aging effects in o-Ps annihilation were measured for approximately $10 \mathrm{~h}$ after quench in both samples, the magnitude of which appears larger in BPA than in TMBPA. We confirmed this result by comparing positron spectra obtained at $23{ }^{\circ} \mathrm{C}$ under minimal $\mathrm{e}^{+}$-exposure time in rejuvenated material with measurements on samples after aging at $T_{\mathrm{g}}-20^{\circ} \mathrm{C}$. An extended analysis indicated that the hole size distribution was indeed shifted significantly during the aging process in BPA, whereas in TMBPA this effect was again found to be much smaller.

Acknowledgment. This research was supported by the U.S. Army Research Office, Contract Number DAAL03-90-G-0023, a research award from Miles, Inc., Pittsburgh, PA, and National Science Foundation Grant Number INT89-15060.

\section{Appendix}

Introducing the apparent o-Ps lifetime $\tau_{3, \mathrm{app}}$, we can write

$$
n_{3}{ }^{\circ}(t)=q_{3}{ }^{\circ} \exp \left(-t / \tau_{3, \mathrm{app}}\right)
$$

Then the difference between the input multiple o-Ps spectrum and the fit is given by

$$
\begin{aligned}
& \Delta n=n_{3}-n_{3}{ }^{\circ}=\sum_{i} q_{3 i} \exp \left(-t / \tau_{3 i}\right)- \\
& q_{3}{ }^{\circ} \exp \left(-t / \tau_{3, \mathrm{app}}\right)
\end{aligned}
$$

or

$\Delta^{2}=\int_{0}^{\infty}\left[\sum_{i} q_{3 i} \exp \left(-t / \tau_{3 i}\right)-q_{3}{ }^{\circ} \exp \left(-t / \tau_{3, \mathrm{app}}\right)\right]^{2} \mathrm{~d} t$

The best fit is determined by the minimization of $\Delta^{2}$, i.e.

$$
\partial \Delta^{2} / \partial q_{3}{ }^{\circ}=0
$$

and

$$
\partial \Delta^{2} / \partial \tau_{3, \mathrm{app}}=0
$$

It follows that

$$
q_{3}{ }^{\circ} \tau_{3, \mathrm{app}}-2 \sum_{i} q_{3 i} \tau_{3, \mathrm{app}} \tau_{3 i} /\left(\tau_{3 i}+\tau_{3, \mathrm{app}}\right)=0
$$

as well as

$$
\begin{aligned}
\left(q_{3}^{\circ}\right)^{2} / 2-2 q_{3} \sum_{i} q_{3 i}\left(\tau_{3 i} /\left(\tau_{3 i}+\tau_{3, \mathrm{app}}\right)-\right. \\
\left.\tau_{3, \mathrm{app}} \tau_{3 i} /\left(\tau_{3 i}+\tau_{3, \mathrm{app}}\right)^{2}\right)=0
\end{aligned}
$$

Combination of eqs a-6 and a-7 yields

$$
\sum_{i} q_{3 i} \tau_{3 i}\left(\tau_{3, \mathrm{app}}-\tau_{3 i}\right) /\left(\tau_{3 i}+\tau_{3, \mathrm{app}}\right)^{2}=0
$$

Since the intensity $I_{3 i}$ in the analysis program is defined as

$$
I_{3 i}=q_{3 i} \tau_{3 i} I_{3} / \sum_{k} q_{3 k} \tau_{3 k}
$$

we obtain with $I_{3} / \Sigma_{k} q_{3 k} \tau_{3 k}=$ constant

$$
\sum_{i} I_{3 i}\left(\tau_{3, \mathrm{app}}-\tau_{3 i}\right) /\left(\tau_{3, \mathrm{app}}+\tau_{3 i}\right)^{2}=0
$$

and with $\tau_{3 i}=\tau_{3, \mathrm{app}}+\Delta \tau_{3 i}$,

$$
\sum_{i} I_{3 i}\left(\tau_{3, \mathrm{app}}-\tau_{3 i}\right) /\left(2 \tau_{3, \mathrm{app}}+\Delta \tau_{3 i}\right)^{2}=0
$$

Since $\sum_{i} I_{3 i}=I_{3}$ and under the assumption $\Delta \tau_{3 i} \ll \tau_{3, \mathrm{app}}$, a single-exponential fit of the multiple o.Ps annihilation yields a numerical value of $\tau_{3, \text { app }}$ which can be approximated by the arithmetical average over all o-Ps components; i.e.

$$
\tau_{3, \mathrm{app}}=\sum_{i} I_{3 i} \tau_{3 i} / I_{3}
$$

Because $n_{i}$ describes the number fraction of free volume holes of size $v_{i}$, it follows that

$$
n_{i}=I_{3 i} / I_{3}
$$

Therefore, we identify $\tau_{3, \text { app }}$ with the number-average lifetime $\left\langle\tau_{3}\right\rangle$, which can be calculated with eqs 1 and 7 from the input parameters of the simulation.

$$
\left\langle\tau_{3}\right\rangle=\sum_{i} n_{i} \tau_{3 i}
$$

\section{References and Notes}

(1) Simha, R.; Somcynsky, T. Macromolecules 1969, 2, 342.

(2) McKinney, J. E.; Simha, R. Macromolecules 1976, 9, 430.

(3) Vleeshouwers, S.; Kluin, J.-E.; McGervey, J. D.; Jamieson, A. M.; Simha, R. J. Polym. Sci., Polym. Phys. 1992, 30, 1492.

(4) Struik, L. C. E. Physical Aging in Amorphous Polymers and Other Materials; Elsevier; Amsterdam, The Netherlands, 1978.

(5) Hautojärvi, P., Ed. Positrons in Solids; Springer: New York, 1979.

(6) McGervey, J. D.; Walters, V. F. Phys. Rev. Lett. 1964, 13, 408.

(7) McGervey, J. D.; Walters, V. F. Phys. Rev. B: Solid State 1970, $B 2,2421$.

(8) Tao, S. J. Chem. Phys. 1972, 56, 5499.

(9) Nakanishi, H.; Jean, Y.C. Positron and Positronium Chemistry; Schrader, D. M., Jean, Y. C., Eds.; Elsevier: Amsterdam, The Netherlands, 1988; p 159.

(10) Nakanishi, H.; Wang, S. J.; Jean, Y. C. Proceedings of the International Conference on Positron Annihilation in Fluids, Arlington, TX; Sharma, S. C., Ed.; World Scientific Publishing: Singapore, 1987, p 292.

(11) Kobayashi, Y.; Zheng, W.; Meyer, E. F.; McGervey, J. D.; Jamieson, A. M.; Simha, R. Macromolecules 1989, 22 (5), 2302.

(12) Deng, Q.; Zandiehnadem, F.; Jean, Y. C. Macromolecules 1992, 25,1090 .

(13) Kluin, J.-E.; Yu, Z.; Vleeshouwers, S.; McGervey, J. D.; Jamieson, A. M.; Simha, R. Macromolecules 1992, 25, 5089.

(14) Zoller, P. J. Polym. Sci., Polym. Phys. 1982, 20, 1453.

(15) Kirkegaard, P.; Pedersen, N. J.; Eldrup, M. RESOLUTION and PATFIT 88, Risø National Laboratory, Denmark, 1989.

(16) Bauer, W.; Major, J.; Weiler, W.; Schaefer, H. E. In Positron Annihilation, Proceedings of the 7th International Conference on Positron Annihilation, New Delhi, India, 1985; Jain, P. C., Singru, R. M., Gopinathan, K. P., Eds.; World Scientific Publishing: Singapore, 1985, p 82.

(17) McGervey, J. D.; Vogel, J.; Sen, P.; Knox, C. Nucl. Instrum. Methods 1977, 143, 435.

(18) Welander, M.; Maurer, F. H. J. In Positron Annihilation, Proceedings of the 9th International Conference on Positron Annihilation, Sombathely, 1992, in press.

(19) Simha, R.; Wilson, P. S. Macromolecules 1973, 6, 908.

(20) Arizzi, S.; Mott, P. H.; Suter, U. W. J. Polym. Sci., Polym. Phys. $1992,30,415$. 